\title{
Gender, Social Origins and Accumulated Disadvantages Associated with Mid-Life Body Weight in Taiwan
}

\author{
Duan-Rung Chen ${ }^{1 *}$, Leah M. Frerichs ${ }^{2}$ \\ ${ }^{1}$ Institute of Health Policy and Management, Public Health Building, National Taiwan University, Taipei, Taiwan \\ ${ }^{2}$ College of Public Health, University of Nebraska Medical Center, Nebraska Medical Center, Omaha, USA \\ Email: duan@ntu.edu.tw, leah.frerichs@unmc.edu
}

Received 23 July 2014; revised 10 September 2014; accepted 26 September 2014

Copyright (C) 2014 by authors and Scientific Research Publishing Inc.

This work is licensed under the Creative Commons Attribution International License (CC BY). http://creativecommons.org/licenses/by/4.0/

c) (7) Open Access

\begin{abstract}
Obesity is a problem with global health and economic consequences. This study assesses the impact of social origins and socio-economic disadvantages on mid-life body weight. Hypotheses of both critical early life period and social trajectory were tested using a sample of 845 adults, aged 45 to 69 years, from a nationally representative sample in 2009 Taiwan Social Change Survey. The study found evidence of a significant gender-specific heterogeneity of social origins on obesity risk. Men with accumulated disadvantage had increased BMI, but no significant accumulative trajectories were found among women. Obesity prevention must consider factors beyond behavioral change, and include a focus on social origins and gender identity.
\end{abstract}

\section{Keywords}

Obesity Risk, Social Class, Social Trajectory

\section{Introduction}

Obesity was once considered a problem of western societies, but has become a problem with global health and economic consequences [1] [2]. In the Asia-Pacific region, Japan, South Korea, and Taiwan each have reported the combined overweight and obesity prevalence (Body Mass Index [BMI] $\geq 25$ ) in adult populations to be between approximately $20 \%$ and $30 \%$ [3]-[5]. Taiwan's childhood prevalence is one of the highest [6]. In the Asia-Pacific region, research shows that socioeconomic status (SES) is associated with obesity risk [7], but the association is not consistent across countries or subgroups [2] [7]. However, research continually shows the ${ }^{*}$ Corresponding author. 
highest obesity rates are most often among the poorest and most poorly educated individuals [7] [8]. Yet, social position at various life phases has differential impact on later life risk [9] [10]. More information regarding obesity risk with different life phases can elucidate how social origins may influence the risk of obesity in order to reverse increasing trends in Asia.

The role of social origins as determinants of adult health has been developed through two conceptual frameworks [11]. The critical period model hypothesizes that certain experiences during childhood may have a permanent imprint in terms of individual biological or behavioral characteristics. Thus, social position at certain time periods may offer specific protection or harm on later life health outcomes. Alternatively, the pathway model hypothesizes that early life disadvantage initiates a chain of negative influences that lead to unfavorable socioeconomic conditions in adulthood, and hereafter elevate the risk of ill-health. Social pathway model recognizes that advantage or disadvantage in one phase of the life course may precede and succeed similar advantage or disadvantage in the other life phases, whereas social mobility recognizes that people can move up or down the social hierarchy across the life course (i.e., from low childhood social position to high adult social position).

Social origins and pathway across the life course are shown to affect adult health [12] [13]. For example, low parental and individual social positions at various life stages (e.g., infancy, adolescence, adulthood) are associated with greater risk of coronary heart disease later in life [13]. The association between social positions across life phases and obesity is not a simple one [9] [10]. A systematic review on the role of childhood social position and adult obesity found evidence in $70 \%$ of studies in females and $27 \%$ in males [14]. Two potential hypotheses are provided [15]. One is from Bourdieu's perspective of "embodiment", suggesting that food and eating were the elaborate reflection of class identity [16]. Within this framework, people experiencing childhood and young adulthood hardships could generate a propensity to look for usefulness and practicality; and it reflects in the choice of nourishing food, which is often heavy, with a high fat content [15]. Another explanation is related to the "thrifty genes" hypothesis, and it suggests that early deprivation and under-nutrition may cause an irreversible change of metabolic systems, resulting in a propensity for calorie storing when faced with food abundance at later ages. Another related hypothesis is about the behavioral responses associated with food insecurity, with a binge-like or "feast-famine" type of eating [15], which results in overeating when food becomes available.

Research on the SES-obesity relationship in Asian societies is scarce. Asian countries have a variety of patterns and trends regarding the association between SES and obesity prevalence, and the SES-obesity relationship most often differs by gender [17] [18]. The goals of this study are: 1) to examine the effect of social origins across life phases on mid-life adulthood BMI; 2) to investigate the role of social pathway on mid-life adulthood BMI.

\section{Methods}

The data is from national representative survey Taiwan Social Change Survey (TSCS) 2009, Phase 5, Wave 5. TSCS is a cross-sectional survey with rotated modules following 5-year cycles and conducted by the Institute of Sociology, Academia Sinica. Trained staff from the Institute of Sociology implemented the TSCS via face-to face interviews in respondents' residence following a weighted sampling scheme to generate a representative sample. The study has been approved by an Ethics Committee of Academia Sinica (AS-IRB-HS07-103039). A total of 2026 respondents completed the survey. Informed consents have been obtained. This study only recruited 845 mid-aged adults, ages 45 to 69 . Adults with no occupation information at any life stage were excluded in the regression analyses.

\subsection{Social Class Schema}

A modified Erikson-Goldthorpe-Portocarero (EGP) 6-class schema [19] is used to determine the social class at childhood, young and midlife adulthood. This classification covers a wide spectrum of occupations based on levels of autonomy and delegated authority in workplace [19]. This indicator was also conceived for international comparisons and used in this context by several European studies [20] [21].

To classify respondent's social origins and current occupations into social classes, this study modified the original eleven EGP (1992) categories into six as follows: 1) EGP I and II, professionals, managers, supervisors of non-manual employees, 2) EGP IIIa + IIIb, routine non-manual class, 3) EGP IVa + IVb, self-employed workers with or without employees, 4) EGP V + VI, manual foremen, supervisors of manual employees, skilled 
workers, 5) EGP VIIa, semi-unskilled manual workers, and 6) EGP IVc + VIIb, self-employed farmers and farm workers. Self-employed farmers and farm workers were combined due to low numbers of farm workers following Taiwan's land reform in the 1950s, which limited meaningful interpretation. Self-employed subjects with or without workers were combined into one category.

\subsection{Dependent Variable}

BMI was calculated from participants' self-reported weight (in kilograms) divided by their height (in square meters).

\subsection{Social Class Variables}

Three life phases used occupational indicators to measure social class (i.e., childhood with father's occupation, young adulthood with occupation at first entry into labor market, and mid-life adulthood with current occupation), and one life course stage used education level (i.e., beginning adulthood with educational attainment).

\subsection{Childhood Social Class}

Childhood social class was measured using father's occupation, which was assessed from the question: "what is/ was your father's main job when you were 15 years old?”

\subsection{Beginning Adulthood Social Class}

Beginning adulthood social class was determined with number of years of education. Educational class used four hierarchical categories 1 ) no formal education ( $\leq 6$ years of schooling), 2) elementary education ( 7 - 9 years of schooling), 3) secondary education (10 - 12 years of schooling), and 4) university degree ( $\geq 13$ years of schooling).

\subsection{Young Adulthood Social Class}

Young adulthood social class was assessed from the question: "what is/was your first main job (40 hours per week) after you finished your school?”

\subsection{Mid-Life Adulthood Social Class}

Mid-life adulthood social class was assessed by the question: “what is your current main job?"

\subsection{Social Accumulation and Mobility}

One indicator for social accumulation and mobility was created based on the four life stage social classes: childhood (via parent occupation), beginning adulthood (via educational attainment), young adulthood (via occupation at entry to labor market), and mid-life adulthood (via current occupation). All four life phase social classes were also dichotomized into high and low categories. Occupations of semi-skilled, unskilled manual, and farmers, and education attainments of no formal education or only primary education (less than 9 years) were classified as low for each respective life stage. Based on the framework provided by Heraclides \& Brunner [10], the indicator was constructed according to the following principle: 1) all life phases (childhood, beginning adulthood, young adulthood, and mid-life adulthood) in high social class was defined as accumulated advantage and all in low social class as accumulated disadvantage; 2) early life phase(s) in high social class followed by subsequent life phase(s) static in low social class was defined as downward mobility; 3) early life phase(s) in low social class and subsequent life phase(s) static in high social class was defined as upward mobility; and 4) moving up and down between low and high social class across life phases was defined as irregular mobility. Additionally, the same principles were followed using a manual versus non-manual occupational status pattern.

\subsection{Statistical Analysis}

The liner regression models were conducted. Standard errors in linear regression analyses were adjusted for data clustering based on the study sample size (i.e., participants were surveyed in 44 to 62 townships ranging from 2 
to 34 respondents per township). Using the sampling weight provided by TSCS, all analyses were undertaken separately for men and women due to evidence of gender-specific effects of social class on obesity. All analyses were conducted with Stata 11.1. Age, gender, marital status, regular exercise and smoking were controlled for each model.

\section{Results}

Table 1 reveals demographic characteristics of the 845 subjects. Most participants were married, with a mean age of approximately 55 years. Sixty-two percent (61.99\%) of men had more than 10 years of education, as compared to only $41.47 \%$ of women. With respect to class distribution, a higher percent of men reported coming from Class I (professional/employer/manager) than women (14.14\% vs. $9.30 \%$ at childhood, $27.12 \%$ vs. $14.45 \%$ at entry to labor market, and $32.20 \%$ vs. $16.35 \%$ at adulthood). However, more women than men were in the Class II (routine non-manual) at entry to labor market and mid-life adulthood ( $23.46 \%$ vs. $6.78 \%$ and $12.32 \%$ vs. $5.81 \%$ respectively), and significantly more women were unemployed/not working at mid-life adulthood (36.02 vs. $12.83 \%)$ likely because they become housewives. Finally, a small portion of respondents (12\% - 15\%) came from the small employers/self-employed background, and remained so in adulthood class.

\subsection{Social Class Effects on Mid-Life Adulthood BMI}

Table 2 provides the effect of early life and young adulthood social class on mid-life adult BMI adjusted for gender, age, marital status, smoking status, and physical activity level. For the early life social class origins, the analysis revealed no significant differences on mid-life BMI among men; however, women raised in Class II (non-manual) had significantly lower mid-life BMIs compared to women raised in Class VI (self-employed worker). Second, in beginning young adulthood phase, as measured by educational attainment class, was significantly related to mid-life BMI for both men and women. Obtaining a college diploma significantly lowered BMI compared to respondents with no formal education. Additionally, men and women who attained Class I (i.e., professional, manager, employer), and women who obtained Class II (i.e., non-manual) occupations at labor market entry had significantly lower mid-life BMIs compared to Class VI (self-employed worker). Lastly, in mid-life adulthood, class was not significantly related to mid-life BMI for women, but men with Class I (professional) occupations had significantly lower BMIs compared to men in Class VI.

\subsection{Social Accumulation and Mobility in the Relation to Mid-Life Adulthood BMI}

Table 3 outlines the analysis results of social accumulation and mobility on mid-life BMI, adjusted for age, gender, marital status, smoking and regular exercise. The effects of social accumulation using high versus low divisions across life stages revealed that accumulated disadvantage increased mid-life adulthood BMI in men (adjusted regression coefficient $=1.337$ ) but not women when compared to the irregular pattern of social mobility. Additional analysis with manual and non-manual division revealed the same significant effect of accumulated disadvantage in men on increased BMI, but no significant effects for women (adjusted regression coefficient $=0.668$ ).

\section{Discussion}

This study is notable in three respects. First, to our knowledge, it is the first to explicitly analyze gender differences with respect to the role of early life conditions as predictors of obesity in a nationally representative sample in Asia. Second, it incorporates the role of early young adulthood (i.e., labor market entry) as significant predictor of adult obesity. Third, it provides evidence that strong gender patterns in the effect of social trajectory on the risk of obesity. Overall, study results further evidence that similar to western societies, social position across the life phases is an important consideration for addressing obesity risk [22]. This study adds several unique gender and life course stage patterns, and the use of social class as an SES indicator provides evidence that different elements of class identity potentially contribute to obesity risk.

Our findings support the critical early childhood period only in women. Many studies indicate the effect of low childhood SES on adult obesity risk is stronger for women than men [9] [23]. Consistent with these findings, this study found a significant effect of childhood class on mid-life adulthood BMI for women (Class II lowered BMI compared to Class VI), but no effects were identified among men. 
Table 1. Socio-demographic characteristics of the study sample $(n=835)$.

\begin{tabular}{|c|c|c|c|c|c|}
\hline & \multicolumn{2}{|c|}{$\operatorname{Men}(N=413,49.47 \%)$} & \multicolumn{3}{|c|}{ Women $(\mathrm{N}=422,50.53 \%)$} \\
\hline & $\mathrm{N}$ or mean & $\mathrm{CI} / \%$ & $\mathrm{~N}$ or mean & (CI/\%) & \\
\hline Age & 54.96 & $(54.31,55.61)$ & 55.13 & $(54.49,55.77)$ & \\
\hline \multicolumn{6}{|l|}{ Marital status } \\
\hline Married & 348 & 84.26 & 328 & 77.73 & * \\
\hline Single & 24 & 5.81 & 28 & 6.64 & \\
\hline Divorced/separated & 34 & 8.23 & 26 & 6.16 & \\
\hline Widow & 7 & 1.69 & 40 & 9.48 & \\
\hline BMI & 24.88 & $(24.58,25.18)$ & 23.80 & $(23.46,24.14)$ & * \\
\hline \multicolumn{6}{|l|}{ Physical inactivity } \\
\hline Yes & 112 & 27.12 & 123 & 29.15 & \\
\hline \multicolumn{6}{|c|}{ Childhood social class (father's occupational class) } \\
\hline I (employer/professional/manager) & 57 & 14.14 & 37 & 9.30 & * \\
\hline II (routine non-manual) & 19 & 4.71 & 22 & 5.53 & \\
\hline III (skilled manual) & 46 & 11.41 & 29 & 7.29 & \\
\hline IV (unskilled manual) & 39 & 9.68 & 46 & 11.56 & \\
\hline V (agriculture workers) & 159 & 39.45 & 192 & 48.24 & \\
\hline VI (small employers/self-employed) & 83 & 20.60 & 72 & 18.09 & \\
\hline \multicolumn{6}{|c|}{ Beginning adulthood class (educational attainment) } \\
\hline$\leq 6$ years & 92 & 22.28 & 173 & 41.00 & * \\
\hline 7 - 9 years & 65 & 15.74 & 74 & 17.54 & \\
\hline $10-12$ years & 196 & 47.46 & 136 & 32.23 & \\
\hline$\geq 13$ years & 60 & 14.53 & 39 & 9.24 & \\
\hline \multicolumn{6}{|c|}{ Young adulthood social class (occupational class at labor market entry) } \\
\hline I (employer/professional/manager) & 112 & 27.12 & 61 & 14.45 & ${ }^{*}$ \\
\hline II (routine non-manual) & 28 & 6.78 & 99 & 23.46 & \\
\hline III (skilled manual) & 58 & 14.04 & 27 & 6.40 & \\
\hline IV (unskilled manual) & 109 & 26.39 & 122 & 28.91 & \\
\hline V (agriculture worker) & 40 & 9.69 & 50 & 11.85 & \\
\hline VI (small employers/self-employed) & 64 & 15.50 & 52 & 12.32 & \\
\hline Unemployed and not working & 2 & 0.48 & 11 & 2.61 & \\
\hline \multicolumn{6}{|c|}{ Mid-life social class (current occupational class) } \\
\hline I (employer/professional/manager) & 133 & 32.20 & 69 & 16.35 & * \\
\hline II (routine non-manual) & 24 & 5.81 & 52 & 12.32 & \\
\hline III (skilled manual) & 43 & 10.41 & 19 & 4.50 & \\
\hline IV (unskilled manual) & 69 & 16.71 & 52 & 12.32 & \\
\hline V (agriculture worker) & 29 & 7.02 & 24 & 5.69 & \\
\hline VI (small employers/self-employed) & 62 & 15.01 & 54 & 12.80 & \\
\hline Unemployed and not working & 53 & 12.83 & 152 & 36.02 & \\
\hline
\end{tabular}

*Significant difference between men and women at $\alpha=0.05$. 
Table 2. Adjusted effect on elevated mid-life BMI by social class indicators across the life course.

\begin{tabular}{|c|c|c|c|c|c|c|c|c|}
\hline \multirow{2}{*}{ Variables } & \multicolumn{2}{|c|}{ Model 1} & \multicolumn{2}{|c|}{ Model 2} & \multicolumn{2}{|c|}{ Model 3} & \multicolumn{2}{|c|}{ Model 4} \\
\hline & Men & Women & Men & Women & Men & Women & Men & Women \\
\hline \multicolumn{9}{|c|}{ Childhood social class (father's occupational class) reference group: small employers/self-employed } \\
\hline I (employers/professional/managers) & -0.202 & 0.034 & & & & & & \\
\hline II (routine non-manual) & 0.559 & $-1.981^{*}$ & & & & & & \\
\hline III (skilled manual) & -0.831 & -0.697 & & & & & & \\
\hline IV (semi-/unskilled manual) & -0.871 & -0.029 & & & & & & \\
\hline V (farmers) & 0.494 & -0.271 & & & & & & \\
\hline \multicolumn{9}{|c|}{ Beginning adulthood social class (educational attainment) } \\
\hline \multicolumn{9}{|l|}{ Reference group: no formal education } \\
\hline Elementary & & & -0.07 & -0.028 & & & & \\
\hline Secondary & & & -0.121 & -0.094 & & & & \\
\hline College/university & & & $-0.151^{*}$ & $-0.110^{*}$ & & & & \\
\hline
\end{tabular}

Young adulthood social class (occupational class at labor market entry) reference groups: small employers/self-employed

$\begin{array}{lrr}\text { I (employers/professional/managers) } & -0.864^{*} & -1.226^{*} \\ \text { II (routine non-manual) } & -0.477 & -1.128^{*} \\ \text { III (skilled manual) } & -0.784 & -0.135 \\ \text { IV (semi-/unskilled manual) } & -1.004 & -0.036 \\ \text { V (farmers) } & 1.243^{*} & -0.061\end{array}$

\begin{tabular}{lrc}
\hline Mid-life social class (current occupational class) reference group: small employers/self-employed & & \\
\hline I (employers/professional/managers) & $-1.133^{*}$ & -0.242 \\
II (routine non-manual) & -0.555 & -0.699 \\
III (skilled manual) & -1.143 & -1.304 \\
IV (semi-/unskilled manual) & -0.903 & -0.369 \\
V (farmers) & -0.287 & -0.605 \\
\hline
\end{tabular}

All models are adjusted for marital status, age, smoking and no regular exercise. ${ }^{*} P<0.05,{ }^{* *} P<0.01$.

Additionally, this study identified beginning and young adulthood period effects on obesity risk for both genders. Obtaining a college degree and obtaining a Class I occupation at young adulthood lowers BMI at midlife for both men and women. This parallels findings in a recent US study that found persistent social disadvantage during the transition from adolescent to young adulthood increased the risk of obesity persistence for both males and females [24]. Further, both genders in this study obtain the highest occupational class in their labor market entry period had significantly lower BMIs in mid-life adulthood. Specific achievements in young adulthood stages imply an increased sensitivity to the influence of external agents that may have crucial effects on later health.

The professional occupational social class for men seems to have a unique health protection value. As compared to self-employed class, men obtain a professional and managerial occupational job had lower BMIs, but women show no significant difference. A recent Taiwanese study provides evidence that gender-specific responses to health are likely mediated by socially and culturally constructed gender role expectations with respects to marriage and work [25]. Women of ages 20 - 29 have a higher labor force participation rate than their male counterparts, however; the trend is reversed for the 30 - 34 age groups and above [22]. As indicated in government 
Table 3. Adjusted effect of social accumulation and mobility on mid-life BMI.

\begin{tabular}{lcc}
\hline & Men & Women \\
\hline Trajectory of social accumulation across life course stages (high vs low categorization) & & \\
\hline Accumulation/mobility pattern reference group (irregular mobility) & & 0.471 \\
Accumulated disadvantage & $1.337^{* *}$ & -0.346 \\
Accumulated advantage & 0.406 & -0.223 \\
Upward mobility & 0.655 & 0.162 \\
\hline Downward mobility & 0.342 & -0.115 \\
\hline Trajectory of social accumulation across life course stages (manual vs. non-manual) & & -0.895 \\
\hline Accumulation/mobility pattern reference group (irregular mobility) & & 1.741 \\
Accumulated disadvantage & $0.668^{*}$ & -0.441 \\
Accumulated advantage & -0.578 \\
\hline Upward mobility & 1.189 & 0.102 \\
Downward mobility & & \\
\hline
\end{tabular}

All models are adjusted for marital status, age, smoking and no regular exercise. ${ }^{*} P<0.05,{ }^{* *} P<0.01$.

records, the current average age of first marriage is 29.2 for women [26], and only about one-third of married women remain employed after marriage [27]. The percentage of women who chose to quit a full-time job after marriage is even higher than those of Japan and other Western countries such as Germany, Norway [27]. Conversely, Taiwanese men participate in the labor market at higher rates, long terms and are traditionally the primary financial earner of the family unit [27]. Thus, most women remain single when entering the labor market at young adulthood, but the high value of marriage, motherhood, and family caregiving responsibilities implied in women's role likely reduces the importance of occupational class and its influence on behavior and health in mid-life [28].

Finally, this study found supports for the trajectory hypothesis only in men. Thus far, research on these processes has had mixed findings. Heraclides \& Brunner [10] found that downward mobility and accumulated disadvantage was significantly associated with increased BMI in both men and women; but upward mobility afforded no protection. However, Langenberg et al. [29] found that upward mobility significantly reduced obesity for both men and women.

The significance of accumulated disadvantage for Taiwanese men but not women may be explained by the interaction of low economic resources, biological reactions and psychological burden concurrently. Social trajectory model hypothesizes early childhood disadvantage initiates a chain of negative influences that lead to unfavorable socioeconomic conditions in adulthood. Taiwanese men experiencing childhood and young adulthood hardships could generate a propensity to look for usefulness and practicality; and it reflects in the choice of nourishing food, which is often heavy, with a high fat content [15]. Additionally, Taiwanese men being the traditional wage earners also tend to value a large body size as an indication of strength and dominance. Their dietary habits may be more conducive to the development of obesity, as manual workers who are at the bottom of the social scale; they tend to consider their body as a "work instrument", to be maintained by rich and high-energy nourishment [15]. Additionally, early deprivation and under-nutrition may cause an irreversible change of metabolic systems, resulting in a propensity for calorie storing when faced with food abundance at later ages, and behavioral responses associated with food insecurity such as "feast-famine" type of eating [15] [30] are possible. Lastly, males generally are considered the primary financial earner in Asia countries [28] which they likely view as important to their social identity. Thus, men in low social position throughout the life course may have a perceived sense of failure and accumulation of associated stress that increases their obesity risk [31].

\section{Conclusions}

Despite its important contributions, this study has several limitations. The cross-sectional nature of the design is 
a weakness and causal links cannot be established. Further, the obesity (i.e., height and weight) and social class indicators (i.e., education and occupation) are self-reported, which is subject to error and bias. It is to our advantage that the correlations between self-reported and measured BMI tend to be very high for adults [32]. Selfreported BMI values, if corrected for biases associated with the socio-demographic characteristics of survey respondents, can be used to estimate health risks associated with BMI [33] and this also justifies our use of selfreported BMI values in the present study. Recall bias is a particular concern with the self-report of father's occupation and first job at labor market entry for childhood and young adulthood classification. Finally, the definition of social mobility and accumulation patterns are not consistent across studies, thus limiting the ability to compare and contrast findings.

Despite these limitations, this study has important implications for future research. Future empirical research should explore the interactions and interdependency of social class, social identity and its influence on health. Longitudinal studies with mixed quantitative and qualitative methods would provide stronger information regarding these influences. This study can also guide obesity prevention intervention strategies. Gender-specific interventions are important, but the interaction of gender, social class, and life course stage will be the further focus target populations. For example, the young adulthood phase appears particularly sensitive, and future interventions may consider targeting individuals during their transition to the job market in order to effectively prevent obesity.

Finally, this study's exploration of social class identity also provides a guide for future programming. For example, the impact of physical activity behavior on obesity is important, but cannot fully explain the differences in obesity risk. Thus obesity prevention must consider factors beyond behavioral change, and include a focus on social values and identity and related constructs.

\section{References}

[1] Finucane, M.M., Stevens, G.A., Cowan, M.J., Danaei, G., Lin, J.K., Paciorek, C.J., Singh, G.M., Gutierrez, H.R., Lu, Y. and Bahalim, A.N. (2011) National, Regional, and Global Trends in Body-Mass Index since 1980: Systematic Analysis of Health Examination Surveys and Epidemiological Studies with 960 Country-Years and 9.1 Million Participants. The Lancet, 377, 557-567. http://dx.doi.org/10.1016/S0140-6736(10)62037-5

[2] Popkin, B.M. and Gordon-Larsen, P. (2004) The Nutrition Transition: Worldwide Obesity Dynamics and Their Determinants. International Journal of Obesity, 28, S2-S9. http://dx.doi.org/10.1038/sj.ijo.0802804

[3] Chu, N.F. (2005) Prevalence of Obesity in Taiwan. Obesity Reviews, 6, 271-274. http://dx.doi.org/10.1111/j.1467-789X.2005.00175.x

[4] Yoon, Y.S., Oh, S.W. and Park, H.S. (2006) Socioeconomic Status in Relation to Obesity and Abdominal Obesity in Korean Adults: A Focus on Sex Differences. Obesity, 14, 909-919. http://dx.doi.org/10.1038/oby.2006.105

[5] Yoshiike, N., Seino, F., Tajima , S., Arai, Y., Kawano, M., Furuhata, T. and Inoue1, S. (2002) Twenty-Year Changes in the Prevalence of Overweight in Japanese Adults: The National Nutrition Survey 1976-95. Obesity Reviews, 3, $183-$ 190. http://dx.doi.org/10.1046/j.1467-789X.2002.00070.x

[6] Gill, T. (2006) Epidemiology and Health Impact of Obesity: An Asia Pacific Perspective. Asia Pacific Journal of Clinical Nutrition, 15, 3-14.

[7] McLaren, L. (2007) Socioeconomic Status and Obesity. Epidemiologic Reviews, 29, 29-48. http://dx.doi.org/10.1093/epirev/mxm001

[8] Monteiro, C.A., Moura, E.C., Conde, W.L. and Popkin, B.M. (2004) Socioeconomic Status and Obesity in Adult Populations of Developing Countries: A Review. Bulletin of the World Health Organization, 82, 940-946.

[9] Senese, L.C., Almeida, N.D., Fath, A.K., Smith, B.T. and Loucks, E.B. (2009) Associations between Childhood Socioeconomic Position and Adulthood Obesity. Epidemiologic Reviews, 31, 21-51. http://dx.doi.org/10.1093/epirev/mxp006

[10] Heraclides, A. and Brunner, E. (2010) Social Mobility and Social Accumulation across the Life Course in Relation to Adult Overweight and Obesity: The Whitehall II Study. Journal of Epidemiology Community Health, 64, 714-719. http://dx.doi.org/10.1136/jech.2009.087692

[11] Ben-Shlomo, Y. and Kuh, D. (2002) A Life Course Approach to Chronic Disease Epidemiology: Conceptual Models, Empirical Challenges and Interdisciplinary Perspectives. International Journal of Epidemiology, 31, 285-293. http://dx.doi.org/10.1093/ije/31.2.285

[12] Blane, D. (1999) The Life Course, the Social Gradient, and Health. Social Determinants of Health, 2, 54-77.

[13] Lynch, J. and Smith, G.D. (2005) A Life Course Approach to Chronic Disease Epidemiology. Annual Review of Public 
Health, 26, 1-35. http://dx.doi.org/10.1146/annurev.publhealth.26.021304.144505

[14] Heraclides, A., Witte, D. and Brunner, E.J. (2008) The Association between Father's Social Class and Adult Obesity Is Not Explained by Educational Attainment and an Unhealthy Lifestyle in Adulthood. European Journal of Epidemiology, 23, 573-579. http://dx.doi.org/10.1007/s10654-008-9245-3

[15] Khlat, M., Jusot, F. and Ville, I. (2009) Social Origins, Early Hardship and Obesity: A Strong Association in Women but Not in Men. Social Science \& Medicine, 68, 1692-1699. http://dx.doi.org/10.1016/j.socscimed.2009.02.024

[16] Bourdieu, P. (1984) Distinction: A Social Critique of the Judgment of Taste. Harvard University Press, Cambridge.

[17] Ji, C.Y. and Cheng, T.O. (2008) Prevalence and Geographic Distribution of Childhood Obesity in China in 2005. International Journal of Cardiology, 131, 1-8. http://dx.doi.org/10.1016/j.ijcard.2008.05.078

[18] Chen, D.R. and Wen, T.H. (2010) Socio-Spatial Patterns of Neighborhood Effects on Adult Obesity in Taiwan: A Multi-Level Model. Social Science \& Medicine, 70, 823-833. http://dx.doi.org/10.1016/j.socscimed.2009.11.030

[19] Erikson, R. and Goldthorpe, J. (1992) The Constant Flux: A Study of Class Mobility in Industrial Countries. Oxford University Press, New York.

[20] Kunst, A.E., Groenhof, F., Mackenbach, J.P. and Leon, D.A. (1998) Occupational Class and Cause Specific Mortality in Middle Aged Men in 11 European Countries: Comparison of Population Based Studies. Commentary: Unequal Inequalities across Europe. British Medical Journal, 316, 1636-1642. http://dx.doi.org/10.1136/bmj.316.7145.1636

[21] Mackenbach, J.P., Kunst, A.E., Cavelaars, A.E.J.M., Groenhof, F. and Geurts, J.J.M. (1997) Socioeconomic Inequalities in Morbidity and Mortality in Western Europe. The Lancet, 349, 1655-1659. http://dx.doi.org/10.1016/S0140-6736(96)07226-1

[22] Directorate-General of Budget, Accounting and Statistics (DGBAS) (2010) Yearbook of Manpower Statistics. Executive Yuan, Taipei.

[23] Giskes, K., Van Lenthe, F.J., Turrell, G., Kamphuis, C.B.M., Brug, J. and Mackenbach, J.P. (2008) Socioeconomic Position at Different Stages of the Life Course and Its Influence on Body Weight and Weight Gain in Adulthood: A Longitudinal study with 13-Year Follow-Up. Obesity, 16, 1377-1381. http://dx.doi.org/10.1038/oby.2008.54

[24] Scharoun-Lee, M., Adair, L.S., Kaufman, J.S. and Gordon-Larsen, P. (2009) Obesity, Race/Ethnicity and the Multiple Dimensions of Socioeconomic Status during the Transition to Adulthood: A Factor Analysis Approach. Social Science \& Medicine, 68, 708-716. http://dx.doi.org/10.1016/j.socscimed.2008.12.009

[25] Chen, D.R., Chang, L.Y. and Yang, M.L. (2008) Gender-Specific Responses to Social Determinants Associated with Self-Perceived Health in Taiwan: A Multilevel Approach. Social Science \& Medicine, 67, 1630-1640. http://dx.doi.org/10.1016/j.socscimed.2008.07.017

[26] Department of Household Registration Affair (DHRA) (2010) Monthly Bulletin of Interior Statistics. Ministry of the Interior, Taiwan.

[27] Directorate-General of Budget, Accounting and Statistics, Executive Yuan and Taiwan (DGBAS) (2005) Statistics Paper and Monographs Series [Data File]. Executive Yuan, Taipei.

[28] Chang, L.Y. (2001) Family at the Bedside: Strength of the Chinese Family or Weakness of Hospital Care? Current Sociology, 49, 155-173. http://dx.doi.org/10.1177/0011392101049003010

[29] Langenberg, C., Hardy, R., Kuh, D., Brunner, E. and Wadsworth, M. (2003) Central and Total Obesity in Middle Aged Men and Women in Relation to Lifetime Socioeconomic Status: Evidence from a National Birth Cohort. Journal of Epidemiology and Community Health, 57, 816-822. http://dx.doi.org/10.1136/jech.57.10.816

[30] Huang, S.L., Li, R.H. and Tang, F.C. (2010) Comparing Disparities in the Health-Promoting Lifestyles of Taiwanese Workers in Various Occupations. Industrial Health, 48, 256-264. http://dx.doi.org/10.2486/indhealth.48.256

[31] Brunner, E.J., Chandola, T. and Marmot, M.G. (2007) Prospective Effect of Job Strain on General and Central Obesity in the Whitehall II Study. American Journal of Epidemiology, 165, 828-837. http://dx.doi.org/10.1093/aje/kwk058

[32] McAdams, M.A., Van Dam, R.M. and Hu, F.B. (2007) Comparison of Self-Reported and Measured BMI as Correlates of Disease Markers in US Adults. Obesity, 15, 188. http://dx.doi.org/10.1038/oby.2007.504

[33] Stommel, M. and Schoenborn, C. (2009) Accuracy and Usefulness of BMI Measures Based on Self-Reported Weight and Height: Findings from the NHANES \& NHIS 2001-2006. BMC Public Health, 9, 421. http://dx.doi.org/10.1186/1471-2458-9-421 
Scientific Research Publishing (SCIRP) is one of the largest Open Access journal publishers. It is currently publishing more than 200 open access, online, peer-reviewed journals covering a wide range of academic disciplines. SCIRP serves the worldwide academic communities and contributes to the progress and application of science with its publication.

Other selected journals from SCIRP are listed as below. Submit your manuscript to us via either submit@scirp.org or Online Submission Portal.
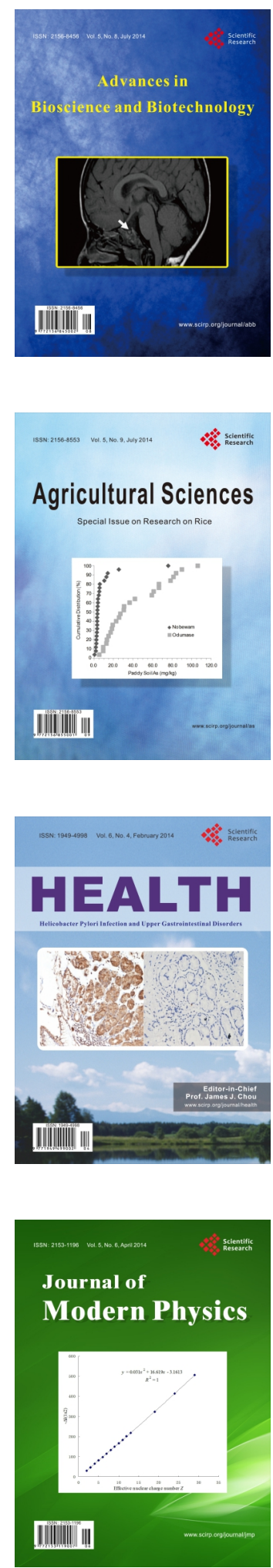
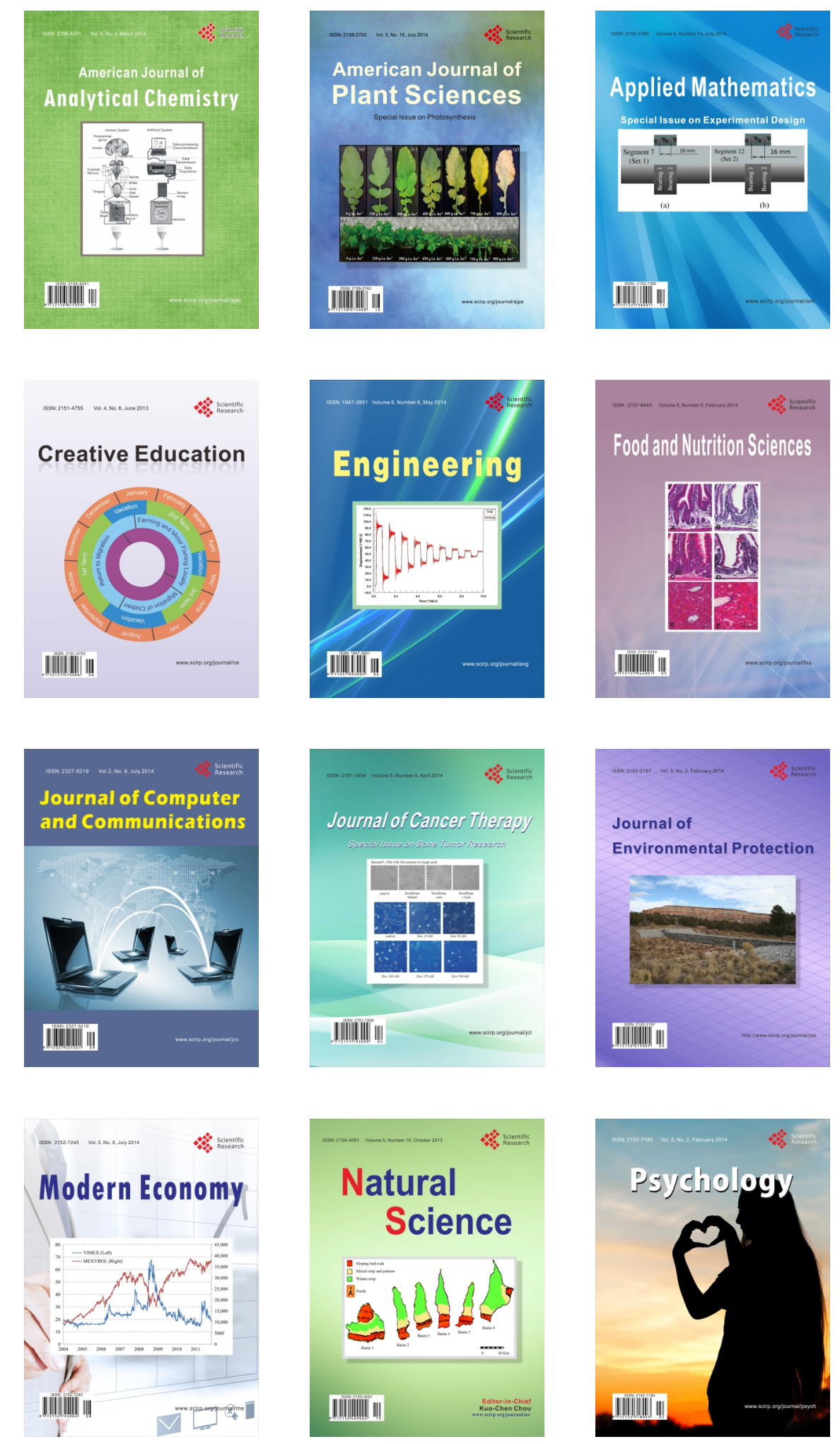